\title{
PENINGKATAN DAYA SAING UKM OLAHAN UBIKAYU: PENDEKATAN RANTAI NILAI
}

\author{
Fitriani $^{1^{*}}$, Bina Unteawati ${ }^{2}$, Sutarni $^{3}$, Cholid Fatih $^{4}$, Zainal Mutaqin $^{5}$ \\ ${ }^{1,3}$ Program Studi Agribisnis Pangan, Politeknik Negeri Lampung \\ Jl. Soekarno Hatta No. 10 Rajabasa, Bandar Lampung, Lampung \\ ${ }^{2,4}$ Program Studi Agribisnis, Politeknik Negeri Lampung \\ Jl. Soekarno Hatta No. 10 Rajabasa, Bandar Lampung, Lampung \\ ${ }^{5}$ Produksi Tanaman Pangan Politeknik Negeri Lampung \\ Jl. Soekarno Hatta No. 10 Rajabasa, Bandar Lampung, Lampung \\ *Corresponding author: fitriani@polinela.ac.id
}

\begin{abstract}
The strategic food resource in Lampung Province is cassava. This study aims to identify the value chain of cassava processed products in Lampung Province. The research method used is a survey, involved 60 SMEs of cassava as respondents. Data analysis uses a value chain analysis approach. The discussion concluded that the main activities on SME value chains consist of input logistics, including procurement of raw materials in the form of fresh cassava from producer farmers, raw/semi-finished materials, and auxiliary materials. The cassava production center in East Lampung is the leading supplier of fresh cassava for the SME. Operation activities including the use of technology and skilled human resources are the key to SME efficiency. SME uses simple technology; the final handling product needs to adopt a market trend. Output logistics: distribution of products to intermediaries and retail traders through direct delivery. The production of SME needs to improve based on market demand. Marketing and sales activities involve some SME medium-scale already have good market and distribution networks, but not the small scale. Marketing and distribution of products still rely on traditional market networks. Services activities carried out by industry include accuracy in meeting agreements with partners, including procurement or delivery, and the payment. Finally, the supporting activities of SME value chains will depend on the ability to identify supplier partners in the procurement of input, and facility needs furthermore will become a node of business cost and profit efficiency.
\end{abstract}

Keywords: value-chain, cassava, SMEs, logistics

Abstrak: Bahan pangan strategis unggulan Propinsi Lampung adalah ubi kayu.
Penelitian ini bertujuan untuk mengidentifikasi rantai nilai produk olahan ubi kayu di
Propinsi Lampung. Metode penelitian yang digunakan adalah metode survei. Industri
olahan ubikayu skala rumahtangga, mikro dan kecil (UKM) sebanyak 60 responden.
Analisis data menggunakan pendekatan diagram rantai nilai (value chain analysis).
Aktivitas utama pada skema rantai nilai olahan pangan ubi kayu berupa logistik
masukan, meliputi pengadaan raw material berupa ubi kayu segar dari petani
produsen, bahan baku/setengah jadi, dan bahan penolong. Sentra produksi ubi kayu di
Lampung Timur menjadi pemasok utama ubi kayu segar bagi UKM. Operasi
merupakan aktivitas prosesing olahan ubikayu. Teknologi produksi dan handling
produk akhir dilakukan secara manual dan sederhana. Adopsi teknologi produksi dan
adaptasi selera pasar diperlukan untuk peningkatan efisiensi. Logistik keluaran,
dilakukan oleh produsen melalui pengiriman dan pengambilan langsung. Produk
availability pada tingkat produsen dilakukan berdasarkan kemampuan produksi belum
berdasar basis permintaan pelaku pasar. Pada aktivitas pemasaran dan penjualan, 
beberapa UKM skala medium telah memiliki jejaring pasar dan distribusi yang baik, mereka fokus pada ketersediaan pasokan barang jadi yang siap dipasarkan. Pemasaran dan pendistribusian produk masih mengandalkan jejaring pasar tradisional. Aktvitas Layanan merupakan aktivitas yang dilakukan oleh UKM untuk ketepatan dalam memenuhi kesepakatan dengan mitra, meliputi pengadaan atau pengiriman, hingga pembayaran. Aktivitas pendukung rantai nilai UMK olahan ubikayu dalam menemukenali mitra pemasok kebutuhan input dan fasilitas akan menjadi simpul efisiensi biaya dan keuntungan usaha.

Kata Kunci: rantai nilai, ubi kayu, UKM, logistik

\section{PENDAHULUAN}

Bahan pangan strategis unggulan Provinsi Lampung adalah ubi kayu. Ubi kayu merupakan sumber pangan karbohidrat penting subtitusi beras. Produksi ubi kayu Lampung berkontribusi lebih dari 35\%, menjadikan Lampung sebagai sentra penghasil ubi kayu terbesar secara nasional (BPS-Statistics Indonesia, 2015). Kinerja produksi ubi kayu terus mengalami perkembangan yang sangat baik. Produktivitas ubi kayu selama kurun 2007-2014 sebesar 23 ton.ha ${ }^{-1}$ berada di atas produktivitas nasional sebesar 20,1 ton.ha ${ }^{-1}$. Sentra produksi ubi kayu berada di Kabupaten Lampung Tengah (30\%), Lampung Utara (25\%), dan Lampung Timur (18\%) (Badan Pusat Statistik Lampung, 2015).

Hilirisasi pengolahan produk (agroindustri) pangan berbasis ubi kayu pada daerah sentra produksi menjadi solusi strategis bagi persoalan fluktuasi harga ubi kayu segar di tingkat petani. Perbaikan struktur pendapatan petani melalui penciptaan nilai tambah unggulan produksi lokal menjadi penting dalam penguatan kapasitas perekonomian perdesaan. Agroindustri berbasis ubi kayu skala kecil melibatkan lebih banyak pelaku rumah tangga. Agroindustri tapioka, beras siger/tiwul/oyek, mocaf, klanting, opak, kerupuk, dan keripik menjadi sumber diversifikasi sumber pendapatan masyarakat perdesaan yang potensial di Lampung (Hidayat et al., 2016; Indiako et al., 2014; Yunus dan Utami, 2012). Agroindustri pangan skala kecil menengah (UKM) berperan penting dalam peningkatan pendapatan rumah tangga petani di pedesaan.

Ketersediaan dan kontinyuitas bahan pangan subtitusi non-beras di pasar merupakan kunci keberhasilan diversifikasi pangan melalui ketersediaan produk sandingan nonberas. Termasuk dalam kemudahan akses pada tingkat harga dan jumlah bagi masyarakat, baik skala rumah tangga maupun industri. Persoalan manajemen usaha dan pemasaran, belum berorientasi bisnis yang berkelanjutan dan jejaring pasarnya belum terbangun merupakan hambatan pengembangan agroindustri pangan berbasis ubi kayu skala rakyat. Keterbatasan penguasaan teknologi produksi secara modern karena ketidaktersediaan modal dan sumberdaya manusia yang berkualitas menyebabkan agroindustri skala kecil belum mampu memenuhi kebutuhan pasar pada tingkat volume, mutu, waktu, dan tempat yang kontinyu (Adicandra dan Estiasih, 2016; Caesarina dan Estiasih, 2016; Fitriani et al., 2019; Indarwanta dan Pujiastuti, 2011; Novia et al., 2013; Pahlevi et al., 2014; Rangkuti et al., 2015; Surfiana et al., 2014).

Pengembangan sistem dan organisasi pelaku agroindustri pangan sebagai entitas bisnis yang tangguh, kuat, berdaya saing, dan berkelanjutan diperlukan untuk mewujudkan kawasan industri kreatif berbasis ubi kayu. Agroindustri pangan berkontribusi penting dalam peningkatan distribusi pendapatan dan ketahanan pangan rumahtangga. Multiplier efek keberadaan agroindustri pangan terhadap perekonomian lokal terjadi melalui peningkatan nilai tambah (Kharismawanti dan Soejono, 2019), keanekaragaman sumber penerimaan, ketersediaan lapangan usaha, meningkatkan pendapatan (Putri, 2020), dan menjamin ketahanan pangan bagi rumah tangga, serta menurunkan kemiskinan perdesaan.

Oleh karena itu, kajian tentang penilaian rantai nilai bisnis agroindustri pangan skala kecil perlu dilakukan untuk menghasilkan informasi strategis yang menguatkan keberlanjutan agroindustri pangan lokal di masa yang akan datang. Penelitian ini bertujuan untuk mengidentifikasi jejaring rantai pasok bisnis olahan pangan berbasis ubi kayu di 
Provinsi Lampung. Informasi hasil analisis penting sebagai bagian pencapaian Rencana Induk Penelitian (RIP) Polinela dengan bidang unggulan "Pangan" untuk mendukung pengembangan kawasan industri kreatif berbasis kearifan lokal dan pangan olahan yang mendukung peningkatan kesejahteraan dan kehidupan masyarakat.

\section{METODE PENELITIAN}

Penelitian ini dilakukan mulai daerah sentra pemasaran hingga sentra produksi olahan ubi kayu. Responden pelaku pemasaran diambil secara purposive pada setiap level rantai pasok dan lembaga pemasaran yang terlibat dalam pendistribusian hasil agroindustri pangan berbasis ubi kayu. Teknik penentuan responden pemasaran dengan metode snow ball sampling. Jumlah responden pemasaran masing-masing level lembaga pemasaran diwakili oleh tiga pelaku. Informasi yang diperoleh dari sentra pasar akan dirunut untuk mengetahui lokasi produsen (UKM) di sentra produksi olahan pangan di desa dan kecamatan pada berbagai kabupaten di Provinsi Lampung. UKM adalah produsen tiwul/oyek, kerupuk/opak, keripik/ klanting, dan tepung kasava/mocaf. Penelitian ini menggunakan metode survei. Pelaku olahan ubikayu skala rumahtangga, mikro dan kecil sebanyak 60 UKM. Penelitian lapang dilakukan pada bulan April-Juni 2018.

Data yang diperlukan dalam penelitian ini adalah data primer dari UKM dan data sekunder dari instansi terkait. Data primer digali dengan menggunakan panduan kuesioner. Data kualitatif penting dalam mengungkapkan keterkaitan dan pola hubungan antar aktor dalam setiap aktivitas mata rantai, sehingga pemetaan terhadap berbagai hubungan, antar pelaku, bagan alur produk dan informasi, hambatan dan potensi solusi dalam setiap mata rantai nilai dapat tergali dengan efektif. Analisis data menggunakan pendekatan diagram rantai nilai (value chain analysis), meliputi: aliran produk, aliran pendapatan, dan aliran informasi strategis efisiensi rantai nilai olahan pangan berbasis ubi kayu sebagainama penelitian analisis daya saing (Irianto dan Widiyanti, 2012; Nugroho dan Yusri, 2017; Unteawati et al., 2018a).

\section{HASIL DAN PEMBAHASAN}

Rekapitulasi kondisi responden meliputi pelaku UKM olahan pangan skala kecil yang menghasilkan produk utama berbentuk kelanting, keripik, kerupuk, opak, tiwul, mocav, dan tapioka. UKM kerupuk dan kelanting diwakili oleh lebih banyak pelaku. Sementara pelaku usaha mocav dan tapioka hanya dapat diwakili oleh satu orang pelaku. Rataan umur pelaku usaha juga berada pada rentang 37-62 tahun. Pelaku UKM memiliki pengalaman usaha lebih dari 5 tahun, yang berarti secara memadai mendukung keterampilan produksi.

Analisis Local Value Chain (LVC) merupakan analisis rantai nilai bisnis olahan pangan berbasis ubi kayu yang meliputi tiga aktivitas utama yang menentukan keberlanjutan bisnis dalam jangka panjang. Tiga aktivitas utama tersebut meliputi aliran produk, aliran pendapatan dan aliran informasi.

\section{Aliran produk.}

Aliran produk berarti alir komoditas dari hulu bahan bahan baku/raw material berasal kepada pelaku usaha rumahtangga/mikro di perdesaan, hingga alir produk akhir hasil olahan oleh pelaku pasar dari tingkat desa, kecamatan, kabupaten, hingga ibukota propinsi. Proses transformasi raw material dalam proses produksi hingga menjadi produk akhir hingga sampai di tangan konsumen akhir melewati beberapa tahapan.

Tabel 1. Kondisi umur dan pengalaman pelaku usaha (UKM) olahan ubi kayu

\begin{tabular}{lcccccccc}
\hline $\begin{array}{l}\text { Keterangan } \\
\text { (rataan) }\end{array}$ & $\begin{array}{l}\text { Kelanting } \\
(\mathrm{n}=17)\end{array}$ & $\begin{array}{l}\text { Keripik } \\
(\mathrm{n}=4)\end{array}$ & $\begin{array}{l}\text { Kerupuk } \\
(\mathrm{n}=20)\end{array}$ & $\begin{array}{l}\text { Opak } \\
(\mathrm{n}=3)\end{array}$ & $\begin{array}{l}\text { Tiwul/beras } \\
\text { analog }(\mathrm{n}=9)\end{array}$ & $\begin{array}{l}\text { Mocav } \\
(\mathrm{n}=1)\end{array}$ & $\begin{array}{l}\text { Tapioka } \\
(\mathrm{n}=1)\end{array}$ & $\begin{array}{l}\text { Pedagang } \\
(\mathrm{n}=6)\end{array}$ \\
\hline $\begin{array}{l}\text { Umur } \\
\text { (tahun) }\end{array}$ & 45.18 & 42 & 47.48 & 37.67 & 52.33 & 49 & 62 & 46 \\
$\begin{array}{l}\text { Pengalaman } \\
\text { (tahun) }\end{array}$ & 11.94 & 6.75 & 20.80 & 12.33 & 8.00 & 1 & 19 & 5.5 \\
\hline
\end{tabular}

Sumber: Data Primer Diolah, 2018 


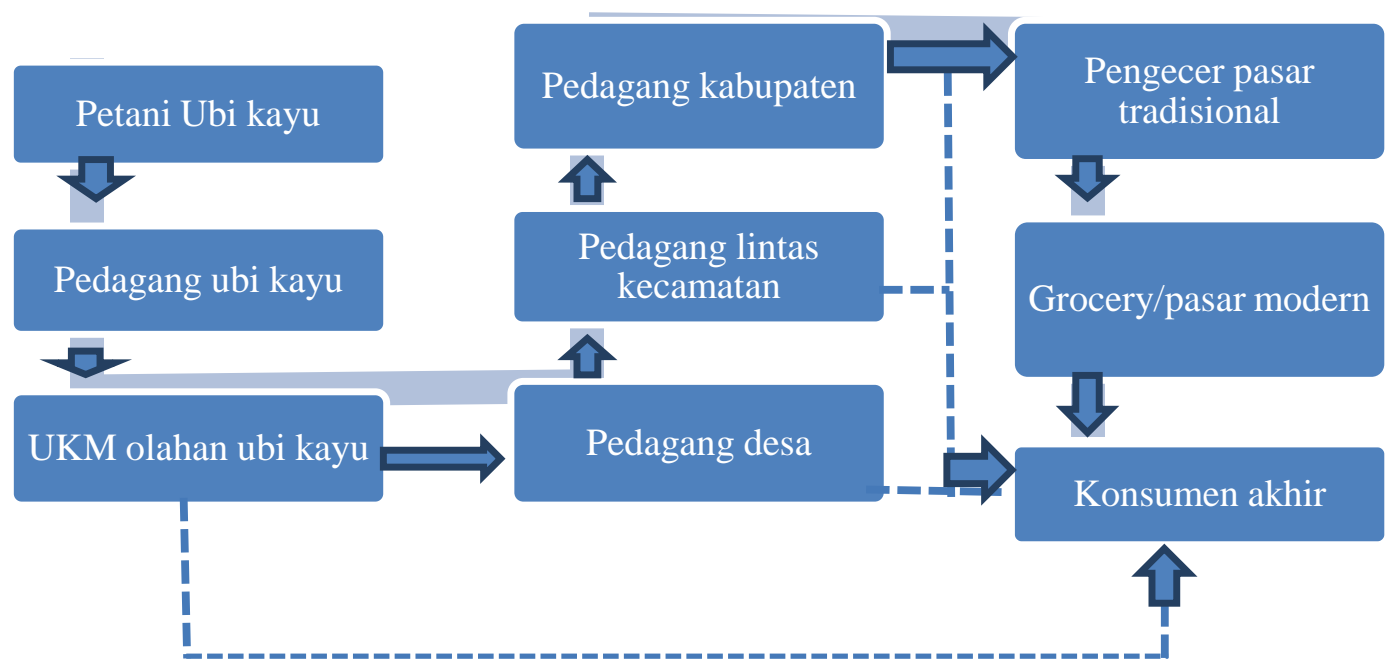

Gambar 1. Aliran produk pada LVC produk olahan ubi kayu Sumber: Data Primer Diolah, 2018

Keterkaitan aliran material komoditas ubi kayu dan olahannya hingga menjadi produk akhir di tangan konsumen secara lengkap dapat dilihat pada Gambar 1.

Pada UKM skala mikro-kecil aliran produk merupakan aliran input raw material dengan rataan penggunaan sebesar $346,7 \mathrm{~kg}$ ubi kayu per peride produksi. Aliran output produk yang dihasilkan rataan mencapai $145 \mathrm{~kg}$. Sementara untuk industri tapioka skala menengah menggunakan input sebesar 20 ton ubi kayu segar per periode produksi untuk output sebesar 111 ton. Pada aliran produk, jenis produk yang dihasilkan, kemudahan memperoleh barang, ketergantungan waktu, dan kemudahan menjual barang menjadi informasi penting yang perlu diperhatikan oleh pelaku UKM olahan ubi kayu.

a. Jenis produk yang dihasilkan

Produk awal yang diperlukan oleh industri olahan ubi kayu skala perdesaan adalah ubi kayu segar yang dihasilkan oleh petani ubi kayu. Daerah asal ubi kayu segar utamanya adalah berasal dari Kabupaten Lampung Timur. Sentra produksi ubi kayu di Kecamatan Batanghari, Labuhan Ratu, Pekalongan, Batanghari Nuban, dan Way Jepara merupakan daerah asal ubi kayu untuk olahan pangan. Selain itu, ubi kayu segar juga diperoleh dari Kabupaten Lampung Tengah utamanya dari
Kecamatan Kalirejo, Punggur, dan Rumbia. Pada Kabupaten Pesawaran berasal dari Kecamatan Gedongtataan, dan Kabupaten Tanggamus berasal dari Kecamatan Sumberejo (Tabel 2).

Tabel 2. Lokasi asal pemasok ubi kayu

\begin{tabular}{l} 
Pemasok ubi kayu \\
\hline Karang Anyar Kec. Gd Tataan, Pesawaran \\
Kec. Sumberejo, Tanggamus \\
Margo Utomo Kec. Labuhan Ratu, Lamtim \\
Sukaraja Nuban, Batanghari Nuban, Lamtim \\
Kec. Jabung, Lamtim \\
Batanghari, Lamtim \\
Sri rejosari, Braja asri, Lamtim \\
Sukosari, Kec. Kalirejo, Lamteng \\
Kec. Rumbia, Lamteng \\
Kec. Punggur, Lamteng
\end{tabular}

Sumber: Data Primer, 2018

Ubi kayu segar yang digunakan untuk UKM olahan pangan berbeda dengan ubi kayu untuk industri. Ubi kayu yang digunakan dikenal dengan nama ubikayu mentega. Ubikayu untuk industri biasanya memiliki kandungan $\mathrm{HCN}$ tinggi. UKM olahan ubi kayu tersebar di berbagai wilayah di Kabupaten Pesawaran, Lampung Tengah, dan Lampung Timur/ Lamtim (Tabel 3). 
Tabel 3. Lokasi produsen olahan ubi kayu

\begin{tabular}{ll}
\hline $\begin{array}{l}\text { Produsen olahan } \\
\text { ubi kayu }\end{array}$ & Produk \\
\hline $\begin{array}{l}\text { Karang Anyar Kec. } \\
\text { Gd Tataan, } \\
\text { Pesawaran }\end{array}$ & $\begin{array}{l}\text { Klanting, keripik, } \\
\text { kerupuk, opak }\end{array}$ \\
Kec. Punggur & $\begin{array}{l}\text { Kelanting, keripik, } \\
\text { opak, tiwul }\end{array}$ \\
Kec. Rumbia & Keripik, opak, tiwul, \\
Kec. Kalirejo & Kerupuk, klanting \\
Kec. Labuhan Ratu & Klanting, tiwul \\
Kec. Pekalongan & Klanting, opak \\
Kec. Batang hari & Klanting, tiwul \\
Kec. Banjarejo & Klanting, tiwul \\
Lamtim & Kerupuk Opak, \\
Kec. Braja Asri, & Mocav \\
\hline Lamtim &
\end{tabular}

Aliran produk olahan ubikayu dari sentra UKM selanjutnya didistribusikan ke berbagai daerah di Propinsi Lampung. Pusat pemasaran produk olahan pangan UKM utamanya adalah di sentra pemasaran di Kota Bandar Lampung, pasar ibu kota kabupaten, pasar kecamatan dan pasar desa (Tabel 4).

Tabel 4. Lokasi pelaku Pasar olahan ubi kayu

\begin{tabular}{ll}
\hline Kabupaten & Desa/kecamatan \\
\hline \multirow{2}{*}{ Lamtim } & Tridatu, Way Jepara, \\
Bandar & Labuhan Ratu, Batanghari \\
Lampung & Panjang, Kedaton, Way \\
& Halim \\
& Sukarame, Kemiling, Teluk \\
& Betung \\
& Gang PU, Bandar Lampung \\
& Gadingrejo, Pringsewu, \\
Pringsewu & Banyumas \\
& Waringinsari, Sukoharjo \\
Pesawaran & Gedungtataan, Wiyono \\
& Sukosari, Kalirejo, \\
Lamteng & Kaliwungu, Punggur \\
& Rumbia \\
Lamsel & Sidomulyo, Kalianda \\
Waykanan & Baradatu \\
\hline Sub: Data Prim
\end{tabular}

Sumber: Data Primer, 2018

b. Kemudahan memperoleh barang

Kemudahan memperoleh sumber pasokan sangat penting untuk kelangsungan usaha. Pasokan ubi kayu segar yang digunakan oleh UKM 88,4\% dikirim langsung dari daerah sentra produksi, sisanya dilakukan pengambilan sendiri oleh pelaku pengolahan. Kondisi ini menggambarkan bahwa aksesibilitas raw material sangat mendukung keberlangsungan UKM ubi kayu di perdesaan.

c. Ketergantungan waktu

Ketersediaan material bahan baku ubi kayu tergantung dengan musim tanam. UKM olahan ubikayu menghendaki kualitas ubi kayu segar dengan umur panen cukup ( $>9$ bulan). Jumlah pasokan ubi kayu segar sulit terpenuhi pada saat musim kemarau. Hubungan baik antara UKM dan pemasok ubi kayu menjadi penting dalam memastikan kecukupan pasokan bahan baku ubi kayu segar. Pada situasi pasokan bahan baku tidak terpenuhi, homeindustri menghadapi kendala kelangkaan bahan baku dan naiknya harga jual. Hal ini dapat mengancam keberlangsungan bisnis UKM di masa datang.

d. Kemudahan menjual barang

Hasil akhir produk olahan ubi kayu selanjutnya dipasarkan. Sebagian besar hasil produksi UKM dikirim langsung ke mitra pedagang $(88 \%)$, hanya sejumlah $12 \%$ yang dilakukan pengambilan oleh pedagang. Sementara itu, pengiriman lanjutan juga dilakukan mitra pedagang, mencapai $80 \%$. Sementara pembeli yang datang ke pedagang mengambil sendiri produk mencapai 20\%. Mitra logistik keluar yang dimiliki oleh pedagang besar rata-rata tiga pedagang ritel, dengan durasi pengalaman bertransaksi selama 6 tahun. Rataan pengambilan 246 pack (@200 gram). Pembayaran umumnya dilakukan secara tunai (90\%) sedangkan lainnya dilakukan secara tempo. Penentuan harga dilakukan secara tawar menawar (20\%), penjual yang menentukan (73\%), dan lainnya pembeli yang menentukan harga (7\%). Kondisi ini menunjukkan bahwa perluasan akses untuk memasarkan produk akhir UKM sangat diperlukan.

\section{Aliran Pendapatan}

Pada Tabel 5 menunjukkan nilai tambah usaha olahan ubikayu yang diterima oleh produsen. Usaha olahan keripik dan kerupuk memberikan bagian nilai tambah paling tinggi dibandingkan 
Fitriani, Unteawati, B., Sutarni, Fatih, C., Mutaqin, Z. : Peningkatan Daya Saing UKM ...

Tabel 5. Nilai tambah (Input-Output) UKM olahan ubi kayu

\begin{tabular}{|c|c|c|c|c|c|c|c|}
\hline Produk & $\begin{array}{l}\text { Output } \\
(\mathrm{kg})\end{array}$ & $\begin{array}{l}\text { Harga } \\
\text { jual } \\
(\mathrm{Rp} / \mathrm{kg})\end{array}$ & $\begin{array}{l}\text { Nilai output } \\
\text { (Rp) }\end{array}$ & $\begin{array}{l}\text { Input } \\
(\mathrm{kg})\end{array}$ & $\begin{array}{l}\text { Harga } \\
\text { input } \\
(\mathrm{Rp} / \mathrm{kg})\end{array}$ & $\begin{array}{l}\text { Nilai input } \\
(\mathrm{Rp})\end{array}$ & $\begin{array}{l}\text { Nilai Tambah } \\
\text { Produk (Rp) }\end{array}$ \\
\hline Kelanting & 100 & 11.471 & 1.141 .661 & 277 & 915 & 253.427 & 888.234 \\
\hline Keripik & 187 & 12.500 & 2.333 .333 & 350 & 1.200 & 420.000 & 1.913 .333 \\
\hline Kerupuk & 346 & 7.380 & 2.552 .890 & 1.028 & 701 & 720.422 & 1.832 .467 \\
\hline Opak & 72 & 8.233 & 590.056 & 355 & 800 & 284.000 & 306.056 \\
\hline $\begin{array}{l}\text { Rice } \\
\text { analog/tiwul }\end{array}$ & 40 & 7.589 & 306.085 & 97 & 978 & 94.736 & 211.349 \\
\hline Mocav & 125 & 7.000 & 875.000 & 1.000 & 400 & 400.000 & 475.000 \\
\hline Tapioka & 111.000 & 3.600 & 399.600 .000 & 20.000 & 720 & 14.400 .000 & 385.200 .000 \\
\hline
\end{tabular}

Sumber: Data Primer Diolah, 2018

Tabel 6. Nilai tambah pelaku pasar (Intermediary Trader) per hari

\begin{tabular}{ccccccrr}
\hline $\begin{array}{c}\text { Intermediary } \\
\text { trader }\end{array}$ & $\begin{array}{c}\text { Output } \\
(\mathrm{kg})\end{array}$ & $\begin{array}{c}\text { Harga } \\
\text { jual } \\
(\mathrm{Rp} / \mathrm{kg})\end{array}$ & $\begin{array}{c}\text { Nilai } \\
\text { output } \\
(\mathrm{Rp})\end{array}$ & $\begin{array}{c}\text { Input } \\
(\mathrm{kg})\end{array}$ & $\begin{array}{c}\text { Harga } \\
\text { input } \\
(\mathrm{Rp} / \mathrm{kg})\end{array}$ & Nilai input (Rp) & $\begin{array}{c}\text { Nilai Tambah } \\
\text { Produk (Rp) }\end{array}$ \\
\hline Level I & 443 & 17.933 & 7.938 .489 & 444 & 12.776 & 5.666 .082 & 2.272 .407 \\
Level II & 359 & 14.117 & 7.405 .368 & 359 & 10.020 & 3.598 .015 & 3.807 .353 \\
Level III & 468 & 7.450 & 3.489 .083 & 468 & 5.403 & 2.530 .561 & 958.522 \\
\hline
\end{tabular}

Sumber: Data Primer Diolah, 2018

olahan kelanting, opak, dan tiwul serta mocav. Sementara untuk industri olahan ubikayu menjadi tapioka memberikan nilai tambah yang tinggi mencapai lebih dari Rp 385 juta.

Pelaku pemasaran produk olahan ubi kayu terdiri dari tiga tingkatan yaitu level I, II, dan III. Pelaku pasar mendapatkan nilai tambah paling tinggi pada level II mencapai Rp 3,8 juta, sedangkan level I mencapai Rp 2,2 juta. Pada level III atau pedagang pengecer mendapatkan bagian lebih kecil (Tabel 6).

Tabel 7. Biaya pemasaran produk akhir olahan ubi kayu (Rp/bulan)

\begin{tabular}{lr}
\multicolumn{2}{c}{ kayu (Rp/bulan) } \\
\hline Biaya pemasaran per bulan & 15.377 \\
\hline Biaya penyusutan peralatan & 769.840 \\
Biaya bahan bakar & 895.833 \\
Biaya TK & 405.667 \\
Biaya kemasan & 36.067 \\
Biaya tali & 48.833 \\
Biaya Retribusi & 497.144 \\
Sewa bulanan & 62.967 \\
Biaya listrik & 833.333 \\
Biaya operasi per hari & 3.565 .061 \\
\hline Total
\end{tabular}

Sumber: Data Primer Diolah, 2018
Pelaku pemasaran mengeluarkan biaya pemasaran meliputi: biaya pengadaan (bahan bakar, tenaga kerja, kemasan, tali), penyusutan peralatan, retribusi, sewa dan listrik bulanan serta biaya operasional harian. Rataan biaya pemasaran yang dikeluarkan oleh pelaku pasar mencapai per bulan mencapai Rp 3,5 juta (Tabel 7).

Selanjutnya berdasarkan informasi kuantitas produk yang diperdagangkan harian maka dalam satu bulan volume perdagangan mencapai $14.356 \mathrm{~kg}$. Pada kondisi ini biaya pemasaran yang dibebankan kepada produk mencapai $\mathrm{Rp} 250 / \mathrm{kg}$ (Tabel 8).

Tabel 8. Rataan biaya pemasaran produk olahan ubi kayu ( $\mathrm{Rp} / \mathrm{kg})$

Biaya pemasaran per bulan $\quad \mathrm{Rp} 3.565 .061 /$ bulan Kuantitas (Q)

penjualan/hari $(\mathrm{kg})$

Kuantitas (Q)

penjualan/bulan $(\mathrm{kg})$ 14.356

Biaya/kg(Rp) 248,34

Sumber: Data Primer Diolah, 2018

\section{Aliran Informasi}

Kelangsungan bisnis sangat ditentukan oleh aliran informasi yang berasal dari konsumen 
akhir. Standar kualitas, harga, volume, aksesibilitas terhadap produk yang diinginkan konsumen menjadi pijakan awal dalam pengembangan produk yang dihasilkan oleh industri. Preferensi konsumen terhadap produk akhir olahan ubi kayu akan memastikan permintaan pasar. Oleh karena itu, penting bagi industri untuk selalui melakukan berbagai upaya menangkap selera dan perkembangan terkini yang diinginkan konsumen. Selera pasar meliputi segala apa yang diinginkan konsumen, rasa, bentuk, kemasan, ukuran yang seperti apa sesuai dengan keinginan konsumen. Kegiatan riset pasar dapat dilakukan dengan menanyakan secara langsung kepada responden termasuk informasi harga yang cocok bagi konsumen. Aliran informasi ini akan melibatkan berbagai pelaku usaha, pemasok, perantara, produsen, hingga konsumen akhir. Kemampuan menangkap akses informasi pasar penting dalam upaya memastikan kelangsungan bisnis yang kompetitif (Fitriani et al., 2019; Unteawati et al., 2018b).

Keberadaan berbagai institusi kelembagaan di desa, kecamatan, dan kabupaten serta propinsi, utamanya dalam keaktifan kelompok wanita tani (KWT), Gapoktan, Asosiasi KWT, Dekranasda kabupaten dan propinsi penting dalam mendukung pengembangan usaha olahan ubi kayu. Kelembagaan UKM perdesaan sangat strategis dalam meningkatkan skala usaha dan menjamin keberlangsungan bisnis bioindustri pedesaan (Fitriani, 2015; Fitriani et al., 2020; Fitriani et al., 2017). Tabel 9 berikut menunjukkan bahwa wanita berperan sangat penting dalam aktivitas produksi dan pemasaran ubi kayu. Keterlibatan wanita dalam rantai ekonomi ubikayu menjadi simpul sumber-sumber pendapatan baru di perdesaan.

Tabel 9. Pelaku usaha olahan ubi kayu berdasarkan gender

\begin{tabular}{lll}
\hline Pelaku usaha & Gender & Responden \\
\hline Industri olahan & Perempuan & 28 \\
& Laki-laki & 31 \\
Pelaku pasar & Perempuan & 44 \\
& Laki-laki & 16 \\
\hline
\end{tabular}

Sumber: Data Primer Diolah, 2018

Pada Gambar 2 dapat dilihat kerangka bekerjanya rantai nilai (value chain) dalam membangun keunggulan bisnis. Skema rantai nilai mengelompokkan aktivitas ke dalam areaarea fungsi bisnis, yaitu ke dalam aktivitas utama dan pendukung.

1. Aktivitas utama (Primary activities), yang berupa:

\section{Analisis struktur dominansi (governance structure)}

\begin{tabular}{|c|c|c|c|c|c|}
\hline \multicolumn{5}{|c|}{ AKTIVITAS UTAMA } & \\
\hline $\begin{array}{l}\text { Inbound } \\
\text { logistics: } \\
\text { a.Raw material } \\
\text { (fresh cassava) } \\
\text { b Bahan baku } \\
\end{array}$ & $\begin{array}{l}\text { Operation: } \\
\text { a.Processing } \\
\text { b Packaging } \\
\text { c.Quality } \\
\text { control. }\end{array}$ & $\begin{array}{l}\text { Outbound } \\
\text { logistics: } \\
\text { a.Pengiriman } \\
\text { dan } \\
\text { pengambilan } \\
\text { pesanan }\end{array}$ & $\begin{array}{l}\text { Marketing } \\
\text { \& Sales: } \\
\text { a.Pasar desa } \\
\text { b Pasar Kec dan } \\
\text { kab//ota } \\
\text { c.Pasar modern. }\end{array}$ & $\begin{array}{l}\text { Services: } \\
\text { a.Layanan pasar } \\
\text { b Layanan } \\
\text { produk } \\
\text { c. Layanan } \\
\text { purna jual. }\end{array}$ & \\
\hline \multicolumn{2}{|c|}{$\begin{array}{l}\text { Pengadaan: } \\
\text { Bahan baku dan penolong }\end{array}$} & \multicolumn{3}{|c|}{ Pengadaan } & NILAI \\
\hline \multicolumn{2}{|c|}{$\begin{array}{l}\text { Teknologi } \\
\text { Peralatan dan metode }\end{array}$} & \multicolumn{3}{|c|}{ Pengembangan Ipteks } & \\
\hline \multicolumn{2}{|c|}{$\begin{array}{l}\text { Pengadaan dan } \\
\text { pengembangan } \mathrm{TK}\end{array}$} & \multicolumn{3}{|c|}{ Manajemen Sumberdaya Manusia } & \\
\hline \multicolumn{2}{|c|}{$\begin{array}{l}\text { Infrastruktur: } \\
\text { Fasilitas keuangan, produksi } \\
\text { dan IT cunnort }\end{array}$} & \multicolumn{3}{|c|}{ Infrastruktur Perusahaan } & \\
\hline
\end{tabular}

Gambar 2. Rantai nilai usaha olahan ubikayu (Skema Porter's) 
Fitriani, Unteawati, B., Sutarni, Fatih, C., Mutaqin, Z. : Peningkatan Daya Saing UKM ...

a. Logistik masukan (inbound logistics): aktivitas yang berhubungan dengan penerimaan, penyimpanan dan menyebarkan masukan. Aktivitas ini meliputi pengadaan raw material berupa ubi kayu segar dari petani produsen, bahan baku/setengah jadi, dan bahan penolong. Hubungan yang terjalin dengan baik antara industri dengan jejaring logistik masukan sangat penting dalam operasi produksi secara berkelanjutan. Kepastian pasokan dalam jumlah, waktu, kualitas, dan harga akan menjadi kunci efisiensi produksi untuk keunggulan dan daya saing usaha.

b. Operasi (operations): aktivitas yang mentransformasikan masukan menjadi keluaran menjadi produk akhir. Aktivitas produksi merupakan transformasi bahan input melalui serangkain proses/tahapan perlakukan sehingga menimbulkan perubahan bentuk dan fungsi dari output atau produk akhir. Penggunaan teknologi dan sumbedaya manusia yang terampil menjadi kunci efisiensi operasi produksi perusahaan.

c. Logistik keluaran (outbound logistics): aktivitas ini berhubungan dengan menyebarkan produk/jasa ke pelanggan. Pendistribusian produk akhir dari industri menjadi muara penerimaan cashflows perusahaan yang berasal dari mitra penyalur/perantara/pedagang. Kemampuan memenuhi permintaan pelanggan dalam jumlah, waktu, kualitas, dan harga serta preferensi/selera pasar/pelanggan akan menjadi kunci keunggulan dan daya saing usaha.

d. Pemasaran dan penjualan (marketing and sales): aktivitas ini berhubungan dengan pemasaran dan penjualan seperti promosi dan sebagainya. Beberapa pelaku industri skala medium telah memiliki jejaring pasar dan distribusi yang baik, mereka fokus pada ketersediaan pasokan barang jadi yang siap dipasarkan. Pelaku UKM olahan ubi belum secara optimal melakukan kegiatan promosi secara terstruktur. Pemasaran dan pendistribusian produk masih mengandalkan jejaring pasar tradisional.

e. Layanan (service): aktivitas yang berhubungan dengan penyedia layanan untuk meningkatkan pemeliharaan produk seperti pelatihan, perbaikan dan perawatan. Aktivitas layanan yang dilakukan oleh industri diantaranya adalah ketepatan dalam memenuhi kesepakatan dengan mitra, meliputi pengadaan atau pengiriman, hingga pembayaran.

2. Aktivitas pendukung (Support activities), yang berupa:

a. Infrastruktur perusahaan (firm infrastructure): aktivitas ini terkait dengan biaya serta aset yang berhubungan dengan manajemen umum, accounting dan keuangan, keamanan dan keselamatan sistem informasi dan fungsi lainnya. Pelaku UKM olahan ubikayu telah melakukan pencatatan keuangan secara manual. Penggunaan IT support masih sangat terbatas.

b. Manajemen sumber daya manusia (human resources management): aktivitas yang terkait dengan penerimaan, pelatihan, pengembangan dan kompensasi untuk semua tipe personil dan mengembangkan tingkat keahlian pekerja. Pelatihan sumberdaya manusia lebih bersifat inhouse training dan internship langsung dalam aktivitas produksi.

c. Pengembangan teknologi (technology development): aktivitas yang terkait dengan biaya yang berhubungan dengan produk, perbaikan proses, perancangan peralatan, pengembangan perangkat lunak komputer, sistem telekomunikasi, kapabilitas basis data baru dan pengembangan dukungan sistem berbasis komputer. Industri olehan ubi kayu di perdesaan sangat memerlukan peningkatan adopsi dan inovasi teknologi produksi dan support IT untuk meningkatkan efisiensi usaha, meningkatkan daya saing, dan keberlanjutan bisnis jangka panjang.

d. Pengadaan (procurement): aktivitas yang terkait dengan bagaimana sumber daya diperoleh dalam value chain organisasi. Kemampuan industri untuk menemukenali mitra pemasok dalam pengadaan kebutuhan input dan fasilitas akan menjadi simpul efisiensi biaya dan keuntungan usaha.

\section{KESIMPULAN}

Skema rantai nilai mengelompokkan aktivitas ke dalam area-area fungsi bisnis, yaitu ke 
dalam aktivitas utama dan pendukung. pada skema rantai nilai olahan pangan ubi kayu berupa: logistik masukan, meliputi pengadaan Aktivitas utama raw material berupa ubi kayu segar dari petani produsen, bahan baku/setengah jadi, dan bahan penolong. Sentra produksi ubi kayu di Lampung Timur menjadi pemasok utama ubi kayu segar bagi UKM. Operasi merupakan aktivitas prosesing olahan ubikayu. Teknologi produksi dan handling produk akhir dilakukan secara manual dan sederhana. Adopsi teknologi produksi dan adaptasi selera pasar diperlukan untuk peningkatan efisiensi. Logistik keluaran, dilakukan oleh produsen melalui pengiriman dan pengambilan langsung. Produk availability pada tingkat produsen dilakukan berdasarkan kemampuan produksi belum berdasar basis permintaan pelaku pasar. Pemasaran dan penjualan: beberapa UKM skala medium telah memiliki jejaring pasar dan distribusi yang baik, mereka fokus pada ketersediaan pasokan barang jadi yang siap dipasarkan. Pemasaran dan pendistribusian produk masih mengandalkan jejaring pasar tradisional. Layanan: aktivitas yang dilakukan oleh UKM diantaranya adalah ketepatan dalam memenuhi kesepakatan dengan mitra, meliputi pengadaan atau pengiriman, hingga pembayaran. Aktivitas pendukung rantai nilai UMK olahan ubikayu dalam menemukenali mitra pemasok kebutuhan input dan fasilitas akan menjadi simpul efisiensi biaya dan keuntungan usaha.

Aktivitas pendukung berupa infrastruktur perusahaan: Pelaku industri olahan ubikayu telah melakukan pencatatan keuangan secara manual. Penggunaan IT support masih sangat terbatas. Manajemen sumber daya manusia terkait dengan pelatihan dan pengembangan tingkat keahlian pelaku usaha masih dilakukan berdasarkan program dari instansi pemerintahan daerah yang tidak terjadwal secara sistematis. UKM yang berada di Kabupaten Lampung tengah telah memiliki inisiasi kemandirian untuk meningkatkan keterampilan pelaku usaha melalui forum Asosiasi Kelompok Wanita Tani. Pelatihan lebih bersifat inhouse training dan internship langsung dalam aktivitas produksi. Pengembangan teknologi pada industri olehan ubi kayu di perdesaan sangat memerlukan peningkatan adopsi dan inovasi teknologi produksi dan support IT untuk meningkatkan efisiensi usaha, meningkatkan daya saing, dan sustainability bisnis dalam jangka panjang. Pengadaan, kemampuan industri untuk menemukenali mitra pemasok dalam pengadaan kebutuhan input dan fasilitas akan menjadi simpul efisiensi biaya dan keuntungan usaha.

Pengembangan UKM olahan pangan perlu terus dilakukan melalui pendekatan terintegrasi antarpemangku kepentingan dalam rantai ekonomi. Membangun sentra pasar olahan UKM pangan menggunakan Ipteks terkini dan teknologi informasi dapat menjadi simpul penting bekerjanya terminal market/market place produk pangan lokal. Penguatan jejaring pasok lokal (Local Value Chains/LVC) dengan mitra pasar dapat menjadi solusi perluasan akses pasar poduk UKM. Integrasi pendekatan bisnis perlu fokus pada market preference, end handling product, dan internet marketing. Kemampuan UKM dalam memanfaatkan teknologi informasi untuk menyiapkan market space dan marketplace pemasaran digital perlu pendampingan secara sistematis dan berkelanjutan dari mitra perguruan tinggi, pemerintah daerah/pusat, dan pelaku usaha.

\section{DAFTAR PUSTAKA}

Adicandra, R. M., \& Estiasih, T. (2016). Beras analog dari ubi kelapa putih: Kajian pustaka. Pangan Dan Agroindustri, 4(1), 383-390.

Badan Pusat Statistik Lampung. (2015). Lampung Dalam Angka, 2015. Bandar Lampung: Lampung Statistical Board.

BPS-Statistics Indonesia. (2015). Statistik Indonesia. Jakarta: BPS Indonesia.

Caesarina, I., \& Estiasih, T. (2016). Beras analog dari Garut (Maranta arundinaceae): Kajian Pustaka. Pangan Dan Industri, 4(2), 498-504.

Fitriani. (2015). Penguatan kapasitas kelembagaan gapoktan melalui pembentukan koperasi pertanian Gapoktan capacity institutionalization through farmer cooperative (koperasi). Masyarakat, Kebudayaan Dan Politik, 
Fitriani, Unteawati, B., Sutarni, Fatih, C., Mutaqin, Z. : Peningkatan Daya Saing UKM ...

28(19), 63-69.

Fitriani, F., Sutarni, S., Trisnanto, T. B., Fatih, C., \& Asnawi, R. (2020). Keberlanjutan finansial usaha beras siger: Studi kasus pada UMK peserta Model Pengembangan Pangan Pokok Lokal (MP3L) di Propinsi Lampung. Journal of Food System and Agribusiness, 3(1), 1523. Retrieved from https://jurnal. polinela.ac.id/index.php/JFA/article/view $/ 1415$.

Fitriani, F., Unteawati, B., \& Fatih, C. (2017). Local processed food industry based cassava in improving rural economy. In Haryanto, I. A., Triyono, S. Waluyo, I. Asmara, S., Suhandy, D., Telaumbanua, M., Saputra, W (Eds.), "Strengthening Food and Feed Security and Energy Sustainability to Enhance Competitiveness" (pp. 155-158). Retrieved from http://repository.lppm.uni la.ac.id/7898/1/2018Dwi Cahyani.pdf.

Fitriani, Sutarni, Unteawati, B., \& Widyawati, D. K. (2019). Polinela smart marketplace untuk penguatan jejaring kluster rantai pasok dan bisnis berkelanjutan. Prosiding Seminar Nasional Pengembangan Teknologi Pertanian IPTEKS, (November), 1-10.

Hidayat, B., Akmal, S., \& Surfiana. (2016). Setting of slice thickness of cassava to improve yield and characteristics of Beras Siger (Modification Tiwul). Jurnal Penelitian Pertanian Terapan, 16(3), 178-185.

Hidayat, D. I. P. (2011). Ketersediaan Pasar Beras Indonesia. Jember: Universitas Jember.

Hidayat, S. (2018). Perimbangan keuntungan dalam rantai pasok agroindustri kelapa sawit. Al-Azhar Indonesia Seri Sains Dan Teknologi, 4(3), 95-104.

Indarwanta, D., \& Pujiastuti, E. E. (2011). Kajian potensi (Study Kelayakan) pengembangan agroindustri di Desa Gondangan Kecamatan Jonalan Klaten. Administasi Bisnis, 8(Januari), 1-13.
Indiako, M. I. S. D. V., Ismono, R. H., \& Achdiansyah. (2014). Studi perbandingan pola alokasi lahan, pengeluaran beras dan pola konsumsi pangan antara petani ubi kayu di desa pelaksana dan non pelaksana Progral MP3L di Kabupaten Lampung Selatan. Jurnal Ilmu-Ilmu Agribisnis, 2(4), 331336.

Irianto, H., \& Widiyanti, E. (2012). Analisis value chain dan efisiensi pemasaran agribisnis jamur kuping Di Kabupaten Karanganyar. SEPA, 9(2), 260-272.

Kharismawanti, I., \& Soejono, D. (2019). Analisis ketersediaan bahan baku dan nilai tambah produk manisan. SEPA: Jurnal Sosial Ekonomi Pertanian Dan Agribisnis, 15(2), 180-191.

Novia, W., Zakaria, W. A. Z., \& Lestari, D. A. H. (2013). Analisis nilai tambah dan kelayakan pengembangan agroindustri beras siger. JIIA (Jurnal Ilmu-Ilmu Agribisnis), 1(3), 210-217.

Nugroho, A. W. D., \& Yusri, J. (2017). Analisis rantai nilai usaha agroindustri ikan patin salai di Desa Penyasawan Kecamatan Kampar Kabupaten Kampar. Jurnal Ilmiah Pertanian, 14(1), 37-49.

Pahlevi, R., Zakaria, W. A., \& Kalsum, U. (2014). Analisis kelayakan usaha agroindustri kopi luwak di Kecamatan Balik Bukit Kabulapen Lampung Barat. Jurnal Ilmu-Ilmu Agribisnis, 2(1), 4855.

Putri, D. D. (2020). Studi komparatif pendapatan, biaya dan kelayakan usaha agroindustri gula semut pada setiap pelaku rantai pemasaran. SEPA: Jurnal Sosial Ekonomi Pertanian Dan Agribisnis, 17(1), 65-71. https://doi.org/ 10.20961/sepa.v17i1.42878.

Rangkuti, K., Mardhiyah, A., \& Putr, A. D. (2015). Analisis nilai tambah keripik singkong pada Kelompok Usaha Keluarga (KUK) Desa Sipare-Pare. Agrium, 19(2), 116-121. 
Fitriani, Unteawati, B., Sutarni, Fatih, C., Mutaqin, Z. : Peningkatan Daya Saing UKM ...

Surfiana, Hidayat, B., \& Akmal, S. (2014). Efektivitas transfer teknologi pengolahan beras sige terhadap peningkatan produktivitas usaha beras tiwul tradisional. Inovasi Dan Pembangunan, 02(03), 32-45.

Unteawati, B., Fitriani, \& Fatih, C. (2018a). Consumer's market analysis of product cassava. International Conference on Biomass: Toward Sustainable Biomass Utilization for Industrial and Energy Applications, (10), 1-11.
Unteawati, B., Fitriani, \& Fatih, C. (2018b). Consumer's market analysis of product cassava. Proceeding 2nd International Conference on Biomass: Toward Sustainable Biomass Utilization for Industrial and Energy Applications, 012033-012042. https://doi.org/10.1088 /1755-1315/141/1/012033.

Yunus, H. A. R., \& Utami, D. P. (2012). Keragaan agroindustri ppak singkong di Desa Jolontoro Kec. Saporan, Kab. Wonosobo. Surya Agritama, I(Maret), 59-70. 